\title{
On the Stability of Deinoxanthin
} Exposed to Mars Conditions during a Long-Term Space Mission and Implications for Biomarker Detection on Other Planets

\author{
Stefan Leuko ${ }^{*}$, Maria Bohmeier ${ }^{1}$, Franziska Hanke', Ute Böettger'2, Elke Rabbow' ${ }^{1}$, \\ Andre Parpart ${ }^{1}$, Petra Rettberg ${ }^{1}$ and Jean-Pierre P. de Vera ${ }^{3}$ \\ 1 German Aerospace Center, Research Group "Astrobiology", Radiation Biology Department, Institute of Aerospace \\ Medicine, Köln, Germany, ${ }^{2}$ German Aerospace Center, Institute of Optical Sensor Systems, Berlin, Germany, ${ }^{3}$ German \\ Aerospace Center, Institute of Planetary Research, Berlin, Germany
}

OPEN ACCESS

Edited by:

Baolei Jia,

Chung-Ang University, South Korea

Reviewed by: James A. Coker,

University of Maryland University College, United States Haitham Sghaier, Centre National des Sciences et Technologies Nucléaires, Tunisia

*Correspondence: Stefan Leuko stefan.leuko@dr.de

Specialty section: This article was submitted to Extreme Microbiology, a section of the journal

Frontiers in Microbiology

Received: 23 May 2017

Accepted: 21 August 2017

Published: 15 September 2017

Citation:

Leuko S, Bohmeier M, Hanke F, Böttger U, Rabbow E, Parpart A, Rettberg P and de Vera J-PP (2017)

On the Stability of Deinoxanthin

Exposed to Mars Conditions during

a Long-Term Space Mission and Implications for Biomarker

Detection on Other Planets.

Front. Microbiol. 8:1680.

doi: 10.3389/fmicb.2017.01680
Outer space, the final frontier, is a hostile and unforgiving place for any form of life as we know it. The unique environment of space allows for a close simulation of Mars surface conditions that cannot be simulated as accurately on the Earth. For this experiment, we tested the resistance of Deinococcus radiodurans to survive exposure to simulated Mars-like conditions in low-Earth orbit for a prolonged period of time as part of the Biology and Mars experiment (BIOMEX) project. Special focus was placed on the integrity of the carotenoid deinoxanthin, which may serve as a potential biomarker to search for remnants of life on other planets. Survival was investigated by evaluating colony forming units, damage inflicted to the $16 \mathrm{~S}$ rRNA gene by quantitative PCR, and the integrity and detectability of deinoxanthin by Raman spectroscopy. Exposure to space conditions had a strong detrimental effect on the survival of the strains and the 16S rRNA integrity, yet results show that deinoxanthin survives exposure to conditions as they prevail on Mars. Solar radiation is not only strongly detrimental to the survival and $16 \mathrm{~S}$ rRNA integrity but also to the Raman signal of deinoxanthin. Samples not exposed to solar radiation showed only minuscule signs of deterioration. To test whether deinoxanthin is able to withstand the tested parameters without the protection of the cell, it was extracted from cell homogenate and exposed to high/low temperatures, vacuum, germicidal UV-C radiation, and simulated solar radiation. Results obtained by Raman investigations showed a strong resistance of deinoxanthin against outer space and Mars conditions, with the only exception of the exposure to simulated solar radiation. Therefore, deinoxanthin proved to be a suitable easily detectable biomarker for the search of Earth-like organic pigment-containing life on other planets.

Keywords: Raman spectroscopy, Deinococcus radiodurans, deinoxanthin, Mars

\section{INTRODUCTION}

The search for evidence of extant or extinct life on Mars by in situ investigations began in 1976 with the landing of the Viking spacecraft (Klein, 1999) and continues today with the curiosity rover investigating whether life was ever present on Mars. The climatic history of Mars can be divided into three main eras, beginning with a water-rich epoch (Noachian; <3.95-3.7 billion years), 
followed by a cold and semi-arid period (Hesperian; 3.72.9 billion years) and transitioning into present-day arid and cold desert conditions (Amazonian; 3.1 billion years to present) (Fairén et al., 2010). Concerning the habitability of Mars, these eras also represent three stages of habitability (Fairén et al., 2010). The Noachian era may represent a potentially habitable epoch, when basic requirements for life as we know it, such as water and energy were present on Mars. The Hesperian era was possibly very challenging for life with liquid solutions evaporating and during the Amazonian era, the surface of Mars has become, except for some subsurface niches (de Vera et al., 2014; Schirmack et al., 2014), uninhabitable to life as we know it. Although there is no definitive proof that life existed on Mars, the possibility is intriguing and the search for signs of extinct or extant life is one of the main focuses of Astrobiologists.

Whenever life-forms were present in an environment, they often leave traces of their former presence in the form of biomarkers. A biomarker can be defined as a chemical species or pattern which is uniquely derived from a living organism (Edwards et al., 2014). Among the most widespread and stable bacterial biomarkers is the class of hopanes (Toporski and Steele, 2002), which are pentacyclic organic compounds found in bacterial membranes where they are used to control cell membrane permeability and aid in their adaptation to extreme environmental conditions (Edwards et al., 2011). Another important group of biomarkers are carotenoids, which can serve as accessory pigments in the light-harvesting complexes of photosynthetic organisms (Tian and Hua, 2010) or scavenge reactive oxygen species like singlet oxygen $\left({ }^{1} \mathrm{O}_{2}\right)$ and peroxyl radicals in non-phototrophic (Armstrong, 1997; Stahl and Sies, 2003; Slade and Radman, 2011). Carotenoids protect DNA from oxidative damage (Shahmohammadi et al., 1998), proteins from carbonylation (Tian et al., 2009), and membranes from lipid peroxidation (Sy et al., 2015). Previous research reports that the ability of oxygen quenching increases with the number of double bonds in the carotenoid molecule, yet quenching varies with chain length, structure, and functional groups (Hirayama et al., 1994). Conjugated keto groups and the presence of a cyclopentane ring increase quenching, while hydroxy, epoxy, and methoxy groups show lesser effects (Hirayama et al., 1994).

Currently, there are two well-established methods to detect and identify carotenoids; the first is detection and separation by HPLC (Tian et al., 2007) and the second is Raman spectroscopy. Raman spectroscopy is a spectroscopic technique used to observe vibrational, rotational, and other low-frequency modes in a molecule. It measures the spectrum of light scattered from a sample, which is irradiated with a monochromatic source in the visible, near-infrared, or UV region (Marshall et al., 2007). Carotenoids are $\pi$-electron-conjugated carbon chain molecules and are similar to polyenes with regard to their structure and optical properties (Marshall et al., 2007). Their strong color is due to an allowed $\pi-\pi^{*}$ transition that occurs in the visible region of the electromagnetic spectrum (Marshall et al., 2007). Carotenoids have two strong Raman bands due to in-phase $v_{1}(\mathrm{C}=\mathrm{C})$ and $\nu_{2}(C-C)$ stretching vibrations of the polyene chain and a medium intensity feature due to in-plane rocking modes of $\mathrm{CH}_{3}$ groups attached to the polyene chain coupled with $\mathrm{C}-\mathrm{C}$ bonds (Gill et al., 1970; Vítek et al., 2009). Because the Raman spectrum results from laser excitation giving rise to a series of characteristic bands in the range of $100-3,500 \mathrm{~cm}^{-1}$, the molecular signatures of biomolecules and minerals occur simultaneously in the same analytical interrogation process (Edwards et al., 2014).

One non-photosynthetic bacterium of significant astrobiological interest, Deinococcus radiodurans, is brightly colored due to the expression of six carotenoid pigments related to $\beta$-carotene, the dominant of which is deinoxanthin (Saito et al., 1998; Ji, 2010; Dartnell and Patel, 2014). Disrupting the synthesis pathway of deinoxanthin by a knock-out of the phytoene synthase $c r t B$ gene results in a colorless mutant which is more susceptible to oxidative DNA-damaging agents than the wild-type (Zhang et al., 2007). D. radiodurans is well known for its extreme resistance against prolonged desiccation, UV and ionizing radiation, oxidative stress, as well as genotoxic chemicals (Battista, 1997; Cox and Battista, 2005; Bauermeister et al., 2012). In particular, the high tolerance against ionizing radiation is perplexing, as there are no naturally occurring environments known that result in exposure exceeding $260 \mathrm{mGy}$ per year (Ghiassi-nejad et al., 2002), making it unlikely that a species evolved mechanisms to protect itself against high dose ionizing radiation (Cox and Battista, 2005). A likely explanation for this extreme radiation tolerance has been suggested by Mattimore and Battista (1996), where the authors proposed that the radiation resistance is a consequence of an adaptation to prolonged desiccation, for example, desiccation, similar to $\gamma$-irradiation, introduces many DNA double-strand breaks into the genome of D. radiodurans (Cox and Battista, 2005). Alternatively, the radiation resistance may have evolved as an adaptation to permafrost or semi-frozen conditions where background radiation-induced DNA damage is accumulated or to high natural ionizing radiation levels in manganese-rich marine sediments (Richmond et al., 1999; Sghaier et al., 2007; Slade and Radman, 2011).

This resistance against desiccation and radiation makes D. radiodurans of high astrobiological interest to investigate the possibility of survival on arid planets such as Mars.

Presently, the International Space Station (ISS) is orbiting Earth in low-Earth orbit (LEO), providing scientists a unique opportunity to study the responses of terrestrial organisms to the space environment. Environmental parameters surrounding the ISS - such as vacuum (between $10^{-3}$ and $10^{-4} \mathrm{~Pa}$ ), intense solar, and cosmic radiation, as well as temperature extremes severely impact the survival of microorganisms (Horneck et al., 2012; Wassmann et al., 2012; Kawaguchi et al., 2013). Due to its resistance against radiation and desiccation, the resistance and response of Deinococcus spp. to simulated (Kawaguchi et al., 2013) or real space conditions (Dose et al., 1995) has been previously investigated. In the frame of the EXPOSE-R2 space mission (see Rabbow et al., 2017), D. radiodurans was exposed to simulated Mars conditions in LEO for 1.5 years as part of the Biology and Mars experiment (BIOMEX). For an in-depth description and goals of the BIOMEX investigations please refer to de Vera et al. (2012). Here we report on the stability and detectability of the biomarker deinoxanthin with Raman spectroscopy, the survival of $D$. radiodurans, and the 
genetic integrity of the $16 \mathrm{~S}$ rRNA gene following exposure to Mars conditions, utilizing the space environment for a realistic simulation.

\section{MATERIALS AND METHODS}

\section{Cultivation}

Deinococcus radiodurans DSM46620 was obtained from the Deutsche Sammlung von Mikroorganismen und Zellkulturen (DSMZ, Braunschweig, Germany). D. radiodurans $\Delta c r t B$ was a kind gift from Prof. Chengxian Fang (College of Life Sciences, Wuhan University, Wuhan, China; Zhang et al., 2007). Both strains were routinely cultured in $2 \times$ TGY medium, composed of (per liter) $10 \mathrm{~g}$ tryptone, $6 \mathrm{~g}$ yeast extract, and $2 \mathrm{~g}$ d-glucose monohydrate, $\mathrm{pH}$ 7.2. For solid medium, $15 \mathrm{~g} / \mathrm{L}$ agar was added to the nutrient solution before autoclaving. Organisms were cultured in $50 \mathrm{~mL}$ medium at $30^{\circ} \mathrm{C}$, shaking at $200 \times g$ for 2 days.

\section{Sample Preparation}

After reaching late exponential phase $\left(\mathrm{OD}_{600 \mathrm{~nm}} \sim 1.0\right)$, samples were centrifuged for $15 \mathrm{~min}$ at $3,000 \times g$ at $4^{\circ} \mathrm{C}$ and the resulting pellet was washed with $25 \mathrm{~mL} 1 \times$ phosphate-buffered saline (PBS), $\mathrm{pH}$ 7.4. Samples were centrifuged again for $15 \mathrm{~min}$ at $3,000 \times g$ at $4^{\circ} \mathrm{C}$ and the resulting pellet was re-suspended in $3 \mathrm{~mL} 1 \times$ PBS. The cell concentration was determined in a Thoma Cell Counter and a working stock of $5 \times 10^{8}$ cells $/ \mathrm{mL}$ was prepared. Forty microliters of this solution was spotted onto quartz disks $\left(\phi 9 \mathrm{~mm}, 1 \mathrm{~mm}\right.$ thickness, $63.61 \mathrm{~mm}^{2}$ area) resulting in a final concentration of $2 \times 10^{7}$ cells/disk. To evaluate possible beneficial effects of embedding cells in sulfatic Mars regolith simulant [S-MRS, composition and Raman spectroscopic properties of the simulant are described in detail by Böttger et al. (2012)], $10 \mathrm{mg} / \mathrm{mL}$ was added to the working solution. After this, the mixture was vortexed (Biovendis, IKA MS3 basic) for $10 \mathrm{~s}$ at full speed $(3,000 \times g)$ before each sample withdrawal to ensure comparable S-MRS distribution, and $40 \mu \mathrm{L}$ was spotted onto quartz disks as described above. A detailed size distribution of the employed S-MRS is given by Baqué et al. (2015). The quartz disks were dried overnight in a clean safety workbench at room temperature $\left(\sim 22^{\circ} \mathrm{C}\right.$ and $\sim 40 \%$ relative humidity). All exposure experiments presented in this work have been conducted with desiccated organisms as described above.

\section{Electron Microscopy}

To analyze the distribution of the simulated Mars regolith on the quartz disks, electron microscopy images were obtained. Samples were prepared as described above and 10 disks were evaluated with a Hitachi TM3000 Tabletop microscope with an acceleration voltage of $15 \mathrm{kV}$. Energy dispersive spectroscopy (EDS) analysis was performed with the program Quantax70 (Bruker).

\section{Extraction of Deinoxanthin}

Cell extracts from $D$. radiodurans containing deinoxanthin were obtained according to a modified protocol of Lemee et al. (1997). Briefly, cells were grown until late-exponential phase $\left(\mathrm{OD}_{600 \mathrm{~nm}}\right.$ $\sim 1.0$ ) and harvested by centrifugation for $20 \mathrm{~min}$ at $4,000 \times g$.
Forty grams of cell pellet was mixed with $200 \mathrm{~mL}$ methanol containing $0.3 \mathrm{~g}$ of 2,6-di-t-butyl-p-cresol (BHT) as antioxidant, homogenized by adding $5 \mathrm{~g}$ of sterilized glass beads and vortexed for $10 \mathrm{~min}$ at $3,000 \times g$. The sample was then centrifuged for $10 \mathrm{~min}$ at $10,000 \times g$ and the supernatant removed. This process was repeated four times until the pellet lost all visible color. Supernatants from this process were pooled and then concentrated via evaporation at $50^{\circ} \mathrm{C}$ for $24 \mathrm{~h}$. Forty microliters was spotted onto similar quartz disks as previously described and the samples were dried overnight in a clean safety workbench at room temperature in darkness.

\section{Pre-flight Ground Tests}

To determine the feasibility of the proposed experiments in space and to optimize sample preparation and analysis, three ground experiments were conducted before the mission, two experiment verification tests (EVTs) and one science verification test (SVT). The tested parameters for the EVTs were as follows: monochromatic $\mathrm{UV}-\mathrm{C}_{(254 \mathrm{~nm})}$ radiation (NN 8/15; Heraeus Noblelight, Hanau, Germany) with fluences of 0, 10, 100, 1,000, and $10,000 \mathrm{~J} / \mathrm{m}^{2}$, and temperatures of -25 and $+65^{\circ} \mathrm{C}$ for $1 \mathrm{~h}$, respectively. A second EVT investigated the effects of simulated solar radiation (achieved with a Wolfram halide lamp with a spectral irradiance in the range of 200-400 nm; Dr. Hoenle AG, Germany) with the following fluences: $0,1.5 \times 10^{3}, 1.5 \times 10^{4}$, $1.5 \times 10^{5}, 5.0 \times 10^{5}$, and $8 \times 10^{5} \mathrm{~kJ} / \mathrm{m}^{2}$, respectively. The SVT consisted of the following parameters: Simulated Martian atmosphere $\left(95.55 \% \mathrm{CO}_{2}, 2.70 \% \mathrm{~N}_{2}, 1.60 \% \mathrm{Ar}, 0.15 \% \mathrm{O}_{2}\right.$, $\sim 370$ ppm $\mathrm{H}_{2} \mathrm{O}$, pressure $10^{3} \mathrm{~Pa}$; Praxair Deutschland $\mathrm{GmbH}$ ) for 38 days with exposure to a simulated solar irradiation fluence of $1.5 \times 10^{6} \mathrm{~kJ} / \mathrm{m}^{2}$. To further simulate the space experiment conditions, samples were placed in three different compartments, which were stacked as: top ( $\mathrm{t}$ ) compartment, where samples were exposed to the full solar radiation spectra, middle $(\mathrm{m})$ and bottom (b) where no solar radiation could penetrate the samples. This arrangement was also employed for the flight and a detailed description of the hardware is given by Rabbow et al. (2012).

\section{Flight Preparation and Mission Ground Reference (MGR) Preparation}

Flight, MGR, and laboratory control samples were prepared from the same starting cultures. Flight and MGR samples were accommodated in the sample trays as described for the SVT test and laboratory controls were stored in the laboratory under ambient conditions $\left(\sim 22^{\circ} \mathrm{C}\right.$ and $\sim 40 \%$ relative humidity) in darkness until the flight sample returned. For flight samples, sample trays were accommodated in Tray II of the EXPOSE-R2 mission. Tray II was hermetically closed, evacuated, and flooded with $980 \mathrm{~Pa}$ pressure Mars gas (described above), and covered by a quartz window with transmission of solar electromagnetic radiation of $\lambda>200 \mathrm{~nm}$, similar to the spectrum expected on the Martian surface. To attenuate the total mission UV fluence, samples were additionally covered with quartz neutral density filter $(0.001 \%$ transmission). These filters were employed due to the results obtained during preliminary experiments (detailed in 
the results section). An identical arrangement of samples was used for the MGR experiment.

\section{Flight Parameters and Conditions}

Samples were transported to Baikonur and launched on 23 August 2014 with the 56P Progress rocket. EXPOSE-R2 was installed on the URM-D platform on Svezda module on 18 August 2014 during the EVA-39 by Aleksandr Skvortsov and Oleg Artemyev. The cover, protecting samples from solar radiation before the start of the exposure period, was removed on 22 October 2014. Samples were outside the ISS for 534 days and exposed to solar radiation for 469 days. During the EXPOSER2 experiment, the height of the ISS varied between 398 and $417 \mathrm{~km}$ above Earth ${ }^{1}$. Over the duration of the mission, the upper surface of the sample trays was exposed to $549.88 \mathrm{MJ} / \mathrm{m}^{2}$ of solar radiation (200-400 $\mathrm{nm}$ ). Due to the previously mentioned neutral density filters, the samples in the top layer were exposed to a fluence of $5.54 \mathrm{~kJ} / \mathrm{m}^{2}$. The trays were returned to the interior of the ISS on 03 February 2016 and the BIOMEX trays arrived back on Earth on 18 June 2016 with the Soyuz 45S rocket. The total mission duration was 696 days from launch to return to ground. An identical arrangement of samples was used for the MGR experiment. During the MGR, the environmental data of the flight unit (e.g., temperature profile and UV exposure) were followed with a time-delay of 2 months within DLR's Planetary and Space simulation facilities (Rabbow et al., 2016). Additional laboratory control samples from the same batch of bacteria were stored in the dark in a desiccator under ambient conditions in the laboratory until the end of the mission and analyzed in parallel to the flight samples.

\section{Sample Analysis \\ Raman Spectroscopy}

After exposure to stress conditions, the detectability of deinoxanthin was determined by Raman spectroscopy. Sample disks were placed under a Raman Microscope (WITec), equipped with a $532 \mathrm{~nm}$ laser. Spectra were routinely obtained by employing $3.02 \mathrm{~mW}$ of laser power. Line scans were performed using the $10 \times$ optical objective and measured over a predetermined distance $(10 \mu \mathrm{m})$ with 50 spectra accumulated with an integration time of $2 \mathrm{~s}$. Each sample was analyzed by five line scans where the area of analysis was randomly chosen, resulting in a total of 250 scans per sample. Following the line scans, area scans were performed over a square of $50 \times 50 \mu \mathrm{m}^{2}$, divided into 25 lines per image with 25 points for each line measured and with $2 \mathrm{~s}$ integration time. All spectra ( 875 in total) were evaluated against predetermined quality criteria (Figure 6).

\section{Survival}

Following evaluation by Raman spectroscopy, the survival by cultivation was assessed by determining the number of colony forming units (CFUs). To remove cells from the quartz disks, the samples on the disks were coated with $30 \mu \mathrm{L} 10 \%(\mathrm{w} / \mathrm{v})$ polyvinylalcohol (PVA) and dried in a sterile safety cabinet at room temperature over-night. The solidified PVA was gently

\footnotetext{
${ }^{1}$ http://www.heavens-above.com/IssHeight.aspx
}

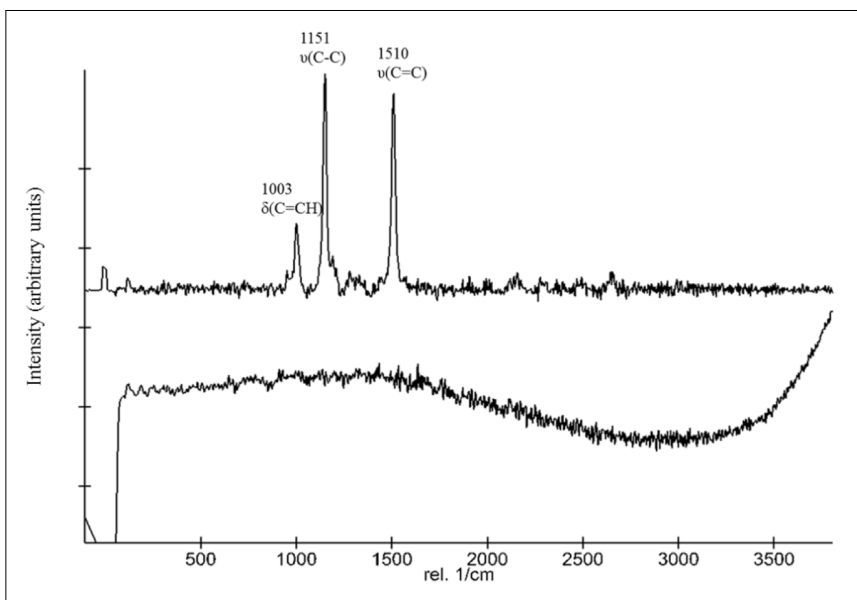

FIGURE 1 | Comparison of Raman spectra of $D$. radiodurans and the $\Delta c r t B$ mutant. The top spectrum was obtained from $D$. radiodurans and the bottom spectrum from the $\triangle c r t B$ strain. The top spectrum shows the distinctive $1,003,1,151$, and $1,510 \mathrm{~cm}^{-1}$ peaks of deinoxanthin.

removed with flame-sterilized forceps and transferred into $500 \mu \mathrm{L} 1 \times$ PBS ( $\mathrm{pH}$ 7.4) buffer. This procedure was repeated three times with samples being stored at $4^{\circ} \mathrm{C}$. Disks were inspected under the microscope ( $\times 60$ magnification) to confirm that no residual samples were left. To investigate survival, $20 \mu \mathrm{L}$ of a dilution series from the recovered samples was plated onto $2 \times$ TGY medium and incubated for up to 1 week at $30^{\circ} \mathrm{C}$ and evaluated daily for growth. The survival rate was calculated as relative survival after exposure to space conditions $(N)$ compared with the untreated laboratory control $\left(N_{0}\right)$.

\section{Integrity of $16 \mathrm{~S}$ rRNA Gene}

DNA from all samples was extracted using the XS-buffer method as previously described by Tillett and Neilan (2000), purified with a standard PCI $(25: 24: 1)$ protocol, precipitated with ice-cold isopropanol and washed twice with $75 \% \mathrm{EtOH}$, and air-dried for $15 \mathrm{~min}$. DNA was re-suspended in $30 \mu \mathrm{L}$ $\mathrm{dH}_{2} \mathrm{O}$ and the concentration was determined with a Nanodrop spectrophotometer (Thermo Scientific, Wilmington, MA, United States) and $10 \mathrm{ng}$ was routinely used as template for quantitative PCR (qPCR). Quantitative PCR was performed following exposure to space conditions and simulated Mars conditions by employing the forward primer Drad16S_F1 (5'-TTTATGGAGAGTTTGATCCTG-3') and the reverse primer Drad16S_R1502 (5'-AAAGGAGGTGATCCAACC-3') resulting in a $1,501 \mathrm{bp}$ product. Primers were designed based on the available type strain sequence. Amplifications were performed in an Opticon2 system (BioRad) using the PeqLab KAPA Sybr FAST Kit. Thermal cycling conditions were: Initial denaturation at $94^{\circ} \mathrm{C}$ for $3 \mathrm{~min}$, followed by 40 cycles of denaturation at $94^{\circ} \mathrm{C}$ for $30 \mathrm{~s}$, primer annealing at $60^{\circ} \mathrm{C}$ for $20 \mathrm{~s}$, and strand extension at $72^{\circ} \mathrm{C}$ for $90 \mathrm{~s}$. The standard curve was calculated on the basis of a $16 \mathrm{~S}$ rRNA gene product obtained from serial diluted $(1: 10 ; 1: 100 ; 1: 1.000$; and 1:10.000), isolated DNA, obtained from a freshly grown WT culture. Melting curve analysis $\left(0.2^{\circ} \mathrm{C} \mathrm{s}^{-1}\right)$ and agarose gel electrophoresis (2\% agarose) 

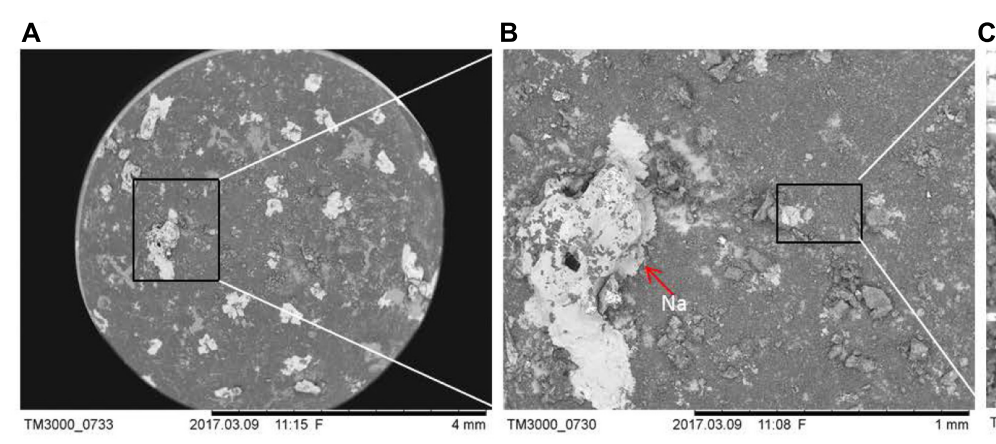

C

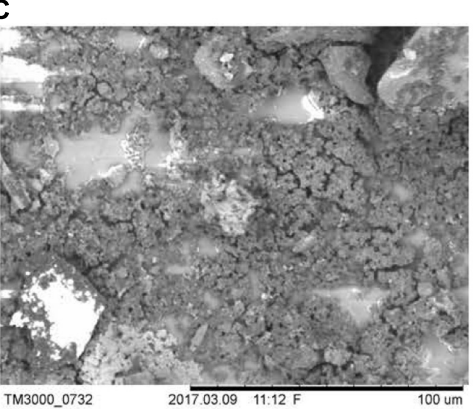

FIGURE 2 | Electron microscopic evaluation of the distribution of the simulated Mars regolith on the quartz sample disks. Image (A) was taken with $\times 25$, (B) with $\times 1,000$, and (C) with $\times 1,500$ magnification, respectively. Elementary analysis was conducted by EDS.

revealed single amplicons for all samples (data not shown). The amplification efficiency $(E)$ was calculated from the slope of the standard curve using the formula: $E(\%)=10^{(-1 / \text { slope) }}-1$ (Bustin et al., 2009). PCR efficiency and correlation coefficient for the standard curve were $81 \%$ and $r^{2}=0.998$, respectively. Resulting values from the $\mathrm{qPCR}$ runs were converted to relative lesion frequencies per $1.501 \mathrm{kB}(\sim 1.5 \mathrm{kB})$ DNA by application of the Poisson distribution (lesions/amplicon $=-\ln \left(A_{\mathrm{t}} / A_{0}\right)$, where $A_{\mathrm{t}}$ represents the amplification of treated samples and $A_{0}$ is the amplification of untreated controls) as previously described (Hunter et al., 2010).

\section{RESULTS}

The suitability of Raman spectroscopy to detect carotenoids is well established. Figure 1 shows representative stacked Raman spectra from the two strains employed in this study. The spectra of the WT contain major features at approximately 1,003, 1,151, and $1,510 \mathrm{~cm}^{-1}$. The bands at 1,510 and $1,152 \mathrm{~cm}^{-1}$ are due to in-phase $\mathrm{C}=\mathrm{C}\left(\nu_{1}\right)$ and $\mathrm{C}-\mathrm{C}$ stretching $\left(v_{2}\right)$ vibrations of the polyene chain in carotenoids. Additionally, in-plane rocking modes of $\mathrm{CH}_{3}$ groups attached to the polyene chain coupled with $\mathrm{C}-\mathrm{C}$ bonds occurred in the $1,003 \mathrm{~cm}^{-1}$ region. The spectra obtained for the $\Delta c r t B$ strain show no distinctive features or peaks, confirming a lack of deinoxanthin or any other Raman active compound under the tested conditions (Figure 1). No significant interference by the S-MRS was detected.

To evaluate if $D$. radiodurans and the $\Delta c r t B$ mutant are suitable candidates for the scientific questions asked by the BIOMEX proposal, several ground tests were conducted. In particular, the stability of deinoxanthin as a biomarker was of higher interest than the survival of the cells. Evaluations of the surface properties of the dried samples combined with the simulated Mars regolith revealed inhomogenic coverage of the quartz disks with cracks within the layers (Figure 2). Experiment verification tests were designed to evaluate if the tested organism survive extreme environments such as radiation, desiccation, and vacuum as foreseen in the space experiment. A SVT was designed to simulate the complete mission in a shorter timeframe on Earth, to evaluate if the chosen organism has the potential of survival, and as a rehearsal for the procedures and logistics. The first EVT focused on the survivability of both strains exposed to monochromatic $\mathrm{UV}-\mathrm{C}_{(254 \mathrm{~nm})}$ radiation as well as temperature extremes as they may occur during the space experiment and the results are given in Figure 3. The second EVT focused on the survival following exposure to simulated polychromatic solar UV radiation with the biologically deleterious spectral irradiance calculated between 200 and $400 \mathrm{~nm}$ and results are presented in Figure 4. The survival of D. radiodurans and the $\Delta c r t B$ mutant displayed a dose-dependent decrease of survival when exposed to germicidal $\mathrm{UV}-\mathrm{C}_{(254 \mathrm{~nm})}$ radiation. A reduction of survival by three orders of magnitude was observed when both strains where exposed to high/low temperature. The addition of simulated Martian soil showed no significant positive or detrimental effect on the survival of both strains under the chosen conditions. Following all exposure experiments, the detectability of the deinoxanthin was evaluated and is shown in Figure 3B. No reduction or shifts in the Raman signal were observed following the described treatment. Similar to exposure to UV-C radiation, exposure to the simulated solar spectrum lead to a dose-dependent decrease in survival and growth was undetected in the timeframe used following exposure up to $8 \times 10^{5} \mathrm{~kJ} / \mathrm{m}^{2}$ (Figure $4 \mathrm{~B}$ ). Again, the addition of simulated Martian soil provided no additional protection. Compared to UV-C $(254 \mathrm{~nm})$ radiation, deinoxanthin is strongly susceptible to simulated polychromatic radiation (Figure 4B). Although the cells survived simulated polychromatic light up to $1.5 \times 10^{4} \mathrm{~kJ} / \mathrm{m}^{2}$, the previously seen signature peaks of deinoxanthin were no longer detectable by Raman spectroscopy following exposure to $1.5 \times 10^{3} \mathrm{~kJ} / \mathrm{m}^{2}$ and higher.

Results from the science verification test (SVT) are given in Figure 5. It is evident from the results that cells in the top layer (exposed to the full solar spectrum), did not survive. This could also be confirmed by the Raman spectra which show no characteristic Raman signals of the WT (Figure 5B). Organisms in the middle and bottom compartment without any exposure to UV radiation survived without any significant loss in viability and deinoxanthin was easily detected. For the reason that both, the cell survival and the Raman signature, are highly affected by polychromatic light, we chose a strong neutral density filter $(0.001 \% \mathrm{~T})$, to reduce the fluence over the duration of the 

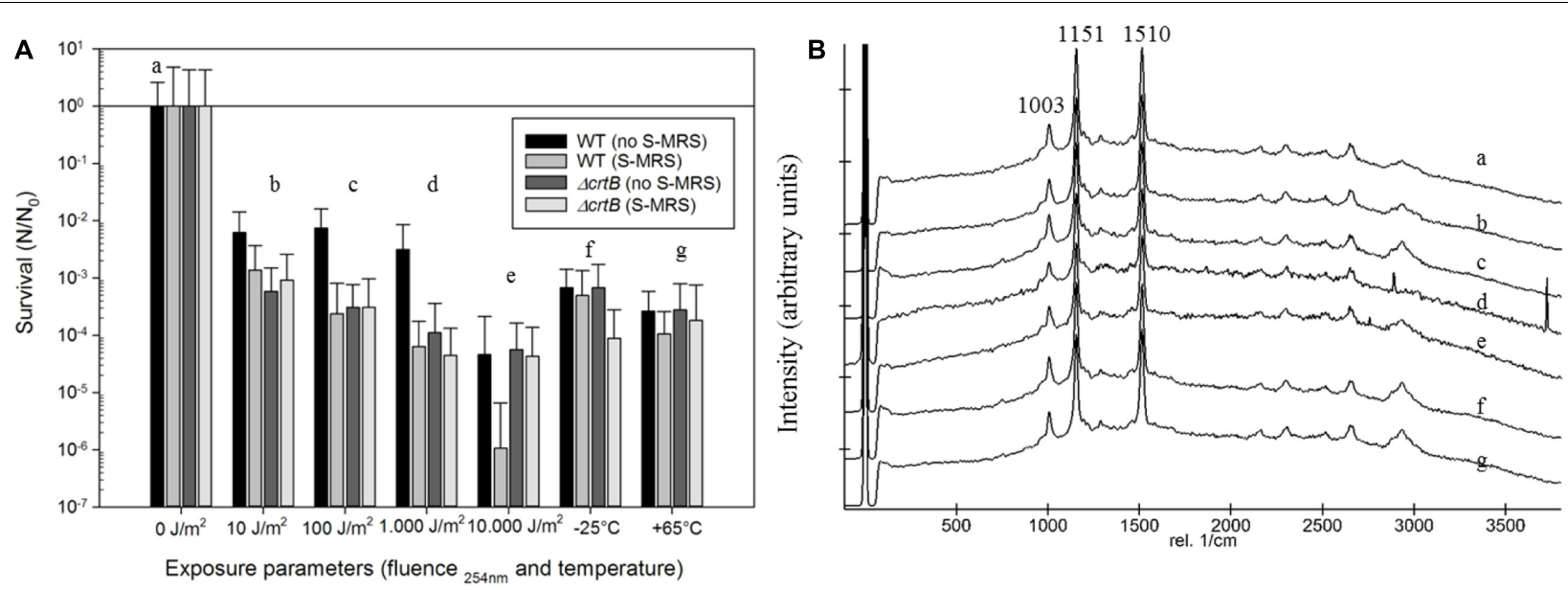

FIGURE 3 | (A) Survival of D. radiodurans and the $\Delta c r t B$ strain following exposure with or without the protection of simulated Martian regolith to $U$ - $\mathrm{C}_{254 \mathrm{~nm}}$ radiation, different temperatures, and simulated Mars-like solar radiation. The survival is given by the quotient $N / N_{0}$, where $N_{0}$ is the number of colonies of the non-treated samples and $N$ that of the exposed samples to the different experimental conditions. (B) Stacked Raman spectra from $D$. radiodurans exposed in the presence of regolith following respective treatments. Small letters (a-g) correspond to the treatment in (A).
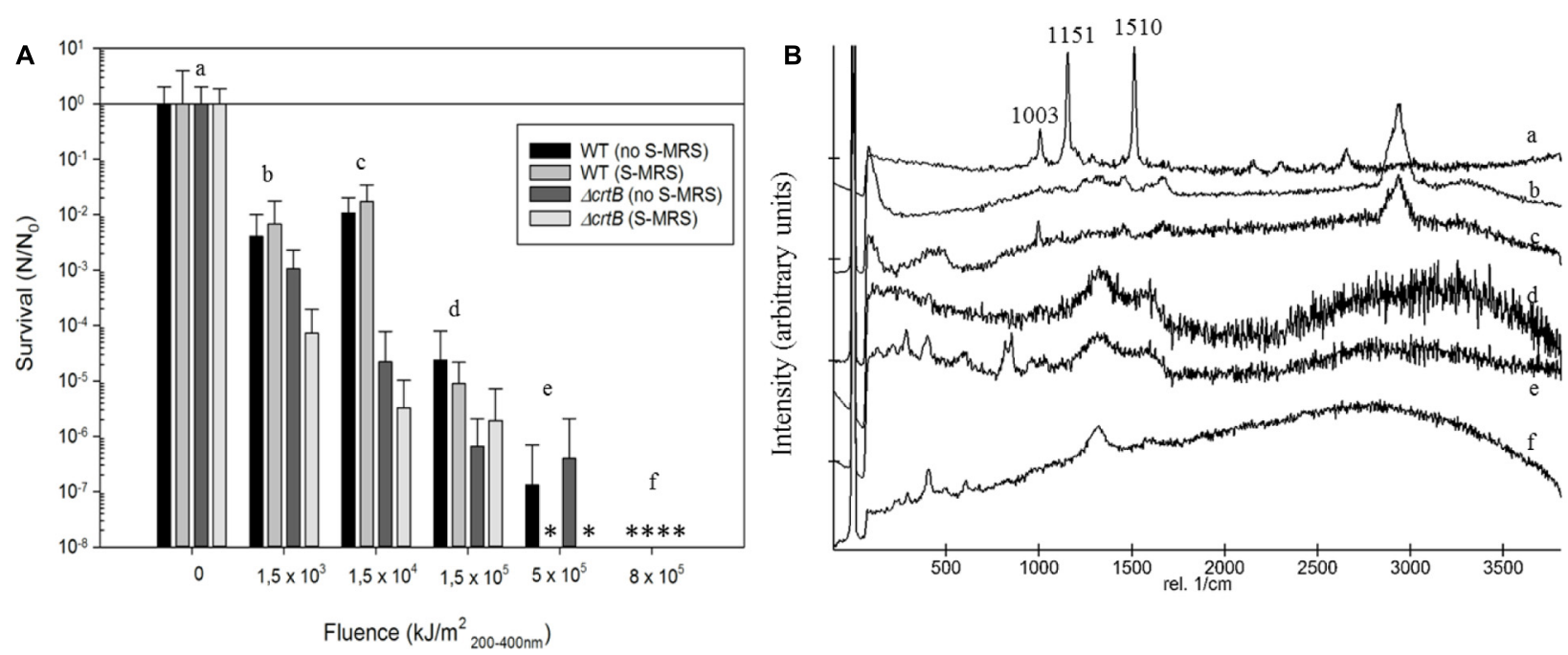

FIGURE 4 | (A) Survival of $D$. radiodurans and the $\Delta$ crtB strain following exposure to simulated solar radiation up to $8 \times 10^{5} \mathrm{~kJ} / \mathrm{m}^{2} . *$ indicates that no survival was observed. The survival is given by the quotient $N / N_{0}$, where $N_{0}$ is the number of colonies of the non-treated samples and $N$ that of the exposed samples to the different experimental conditions. (B) Stacked Raman spectra from D. radiodurans exposed with regolith following respective treatments. Small letters (a-f) correspond to treatment in $\mathbf{( A )}$.

mission. Following the previously mentioned measured fluences, samples were exposed to $5.54 \mathrm{~kJ} / \mathrm{m}^{2}$ solar radiation $(200-400 \mathrm{~nm})$ during the duration of the mission.

Following the return of the samples and the arrival in the laboratory, survival was evaluated immediately and Raman spectra were obtained from all samples. D. radiodurans grows best between 30 and $37^{\circ} \mathrm{C}$, with a doubling time of $1.5-3 \mathrm{~h}$ (Cox and Battista, 2005). Unfortunately, no survival was observed for either the WT or the $\triangle \operatorname{crtB}$ mutant, even after prolonged incubation for up to 3 weeks at $30^{\circ} \mathrm{C}$. Given roughly $21 \times$ longer to grow than a strain maintained under laboratory conditions, we believe that the probability of observing growth from the cells exposed to space conditions is very low. Expectedly, evaluation of the 16S rRNA integrity revealed that the $16 \mathrm{~S}$ rRNA gene suffered severe damage during this process. Results from the laboratory control show that the prolonged desiccation and storage resulted in an $81 \%$ chance of a lesion within the $16 \mathrm{~S}$ rRNA gene, without being exposed to solar radiation or other detrimental factors (Table 1). The stability of deinoxanthin was investigated by Raman spectroscopy and accumulated spectra were divided into four different classes (Figure 6). Spectra of classes 1 and 2 show a strong signal/low noise ratio with the 

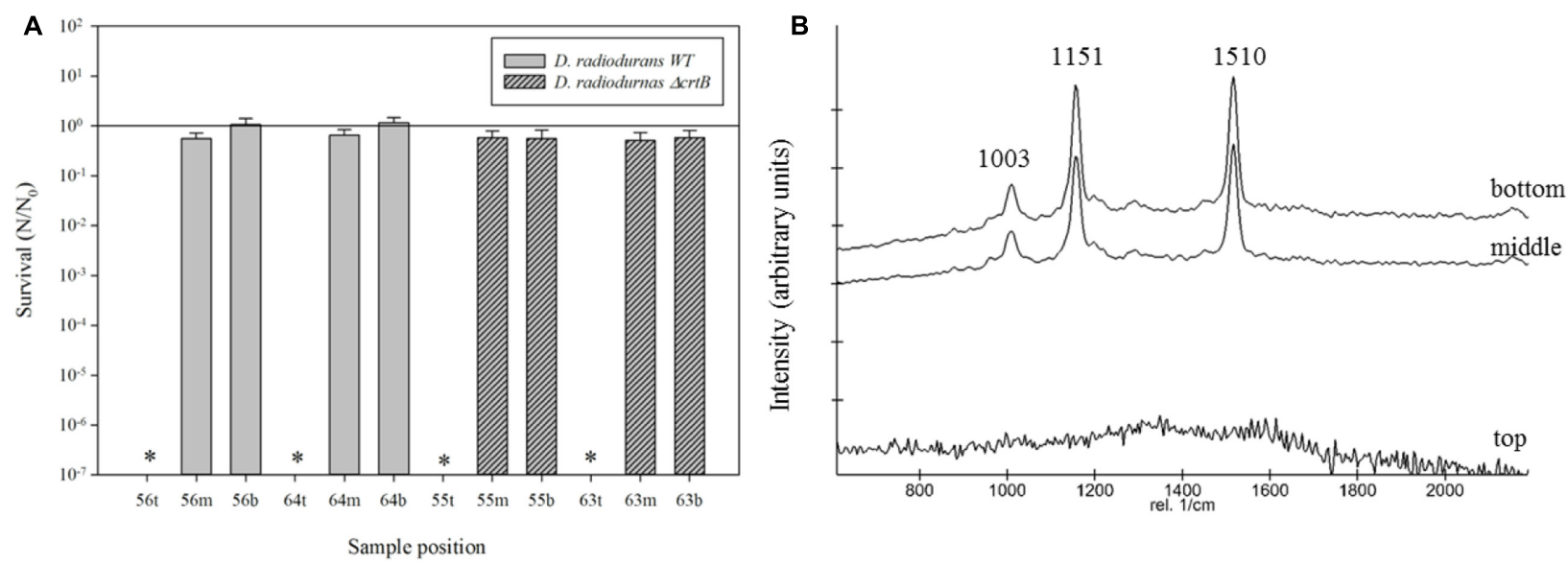

FIGURE 5 | (A) Survival of D. radiodurans and $\triangle$ crtB with regolith following the science verification test (SVT). *Indicates that no survival was observed. (B) Stacked Raman spectra from samples exposed to solar irradiance (top), and no irradiance (middle and bottom).

three characteristic peaks dominating the spectra. Class 3 spectra have a medium signal/noise ration with the peaks fading. Class 4 spectra are classified by a weak signal/noise ratio with the peak at $1,003 \mathrm{~cm}^{-1}$ scarcely detectable. Results of this evaluation are given in Figure 7. For all flight and MGR samples, 875 spectra were obtained and evaluated separately. Samples exposed to solar radiation lost the deinoxanthin signal almost completely, with samples exposed in the space mission marginally better preserved than samples from the MGR (Figure 7). Samples not exposed to solar radiation revealed strong deinoxanthin signals, both after spaceflight and ground simulation. It is interesting to note that the signal from the laboratory control (kept in dark) appears to be significantly weaker $(44.1 \%$ class 1 spectra, compared to 96.7\% class 1 spectra from the ISS bottom sample) compared to spectra from samples not exposed to solar radiation during the space mission. To investigate if deinoxanthin is resistant to detrimental environmental conditions when not protected by the cell, it was extracted from cell homogenate, using methanol and $\mathrm{BHT}$, and the resulting concentrated sample was exposed

TABLE 1 | Relative lesion frequency in the 16S rRNA gene fragment (1.5 kb) calculated against DNA extracted from freshly grown $D$. radiodurans.

\begin{tabular}{lclc}
\hline $\begin{array}{l}\text { Sample } \\
\text { location }\end{array}$ & $\begin{array}{l}\text { Relative lesion } \\
\text { frequency (\%) }\end{array}$ & $\begin{array}{l}\text { Sample } \\
\text { location }\end{array}$ & $\begin{array}{c}\text { Relative lesion } \\
\text { frequency (\%) }\end{array}$ \\
\hline LC WT & $81( \pm 2)$ & LC $\Delta$ crtB & $76( \pm 5)$ \\
ISS WT_t & 100 & ISS $\Delta$ crtB_t & 100 \\
ISS WT_m & 100 & ISS $\Delta$ crtB_m & $65( \pm 3)$ \\
ISS WT_b & $94( \pm 6)$ & ISS $\Delta$ crtB_b & $70( \pm 2)$ \\
MGR WT_t & 100 & MGR $\Delta$ crtB_t & 100 \\
MGR WT_m & $93( \pm 5)$ & MGR $\Delta$ crtB_m & $83( \pm 6)$ \\
MGR WT_b & $89( \pm 1)$ & MGR $\Delta c r t B \_b$ & $81( \pm 3)$ \\
\hline
\end{tabular}

Sample location indicates whether samples were exposed to outer space (ISS) or part of the mission ground reference (MGR). LC denotes a laboratory control from the same batch that was sent to the ISS. Lowercase $t, m$, and $b$ describe the sample position within the tray as follows: t, top; $m$, middle; and b, bottom. Only the top samples were exposed to solar radiation.

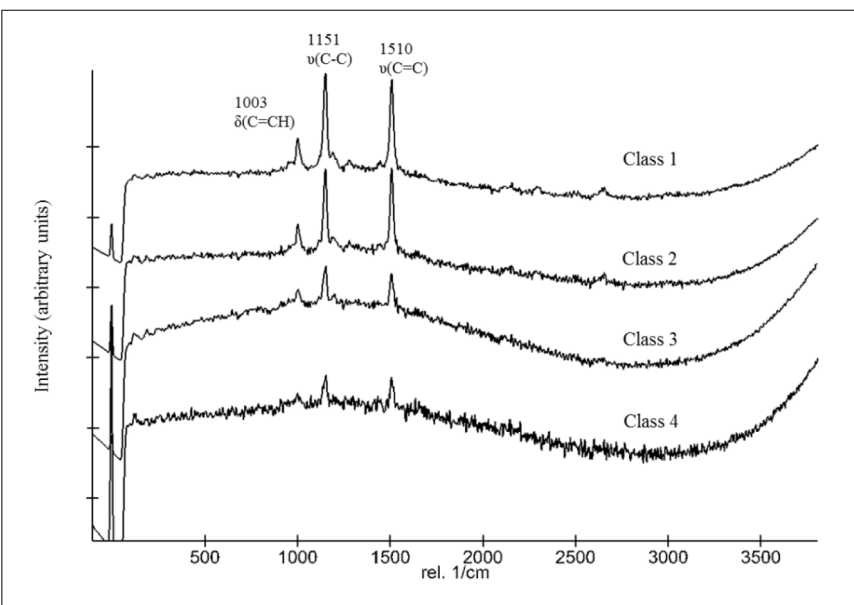

FIGURE 6 | Categorization of spectra and classification in different classes.

to UV-C radiation, vacuum, and different temperature extremes (Figure 8). Exposure to heat, $\left(+90^{\circ} \mathrm{C}\right)$ for $24 \mathrm{~h}$, resulted in a visible quality loss of the spectrum. All other tested factors did not influence the quality of the obtained spectra significantly.

\section{DISCUSSION}

The BIOMEX was aimed at exposing different extremophilic organisms and potential biomarkers to Martian-like conditions in LEO, being simulated in one of the trays as part of the EXPOSER2 mission. Here we report the results of the survival and genetic integrity of $D$. radiodurans and the $\Delta c r t B$ mutant and the stability and detectability of deinoxanthin following the exposure. The main focus of this work was to determine the stability of deinoxanthin and the possibility of this molecule to be a useful biomarker to detect life on other planets. Although both strains survived the preliminary tests relatively well, except intense 


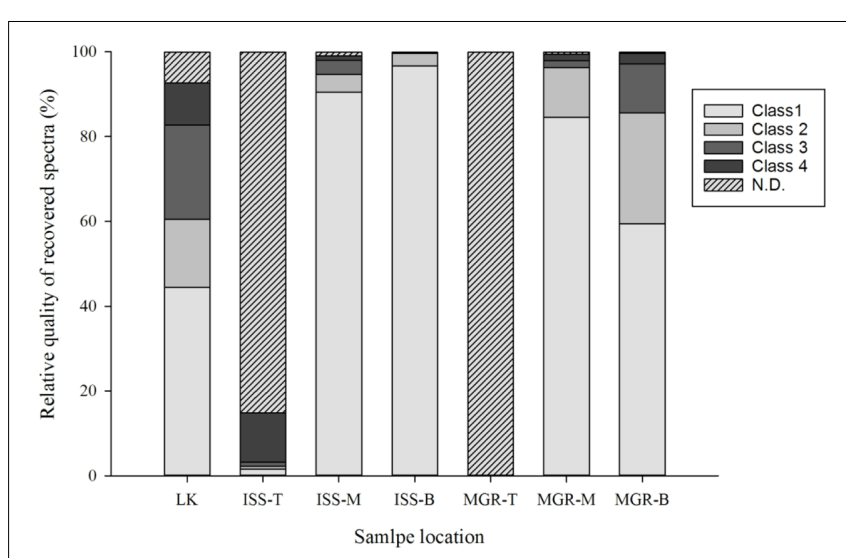

FIGURE 7 | Evaluation of the deinoxanthin signal intensity according to the defined classes (Figure 6) following ground simulations and samples exposed to outer space conditions during the EXPOSE-R2 mission. N.D. denotes that no signal could be determined. Eight hundred and seventy-five spectra were evaluated for each bar and scored according to the previously determined signal class (Figure 6). Sample location indicates whether samples were exposed to outer space (ISS) or part of the mission ground reference (MGR). LK denotes a laboratory control from the same batch that was sent to the ISS. $\mathrm{T}, \mathrm{M}$, and $\mathrm{B}$ describe the sample position within the tray as follows: T, top; $\mathrm{M}$, middle; and B, bottom. Only the top samples were exposed to solar radiation.

exposure to solar radiation, we were not able to recover colonyforming units from any of the samples, not even the laboratory control. It is well established that $D$. radiodurans is desiccation resistant (Cox and Battista, 2005; Bauermeister et al., 2011); however, desiccation for 17 months without protective substances such as glucose and storage in a non-oxidizing atmosphere such as argon lead to a lethal amount of DNA double-strand breaks as previously reported by Dose et al. (1995). Similar to these results, storage of dried $D$. radiodurans and the $\triangle c r t B$ mutant strain in the dark under ambient laboratory conditions lead to an $81 \%$ chance of a lesion within the 16S rRNA gene (Table 1). Exposure to extraterrestrial Mars-like solar UV radiation led to a $100 \%$ probability of a lesion (Table $\mathbf{1}$ ). The addition of the simulated Martian regolith did not improve the survivability of the strains, although a beneficial effect has been previously reported (Pogoda de la Vega et al., 2007); however, our results suggest that a longterm storage of cells embedded in the dust has a detrimental effect on the cells. A possible explanation for this conundrum may be that UVR-induced radicals form in Mars substrates (Shkrob et al., 2010), which might be mimicked by the employed S-MRS and therefore may affect the survivability (Meeßen et al., 2015). It has previously been reported that even multilayers of cells act as a protective barrier for the cells underneath (Kawaguchi et al., 2013); here, however, the impact of prolonged desiccation was sufficient to kill the cells even without exposure to solar radiation.

The picture is different when investigating the stability and detectability of deinoxanthin by Raman spectroscopy. Carotenoids serve as accessory pigments to increase the efficiency of photosystems but are also synthesized by many nonphotosynthetic bacteria as they function as efficient scavengers of ROS (Dartnell et al., 2012). It has previously been shown that deinoxanthin is particularly effective in scavenging $\mathrm{H}_{2} \mathrm{O}_{2}$

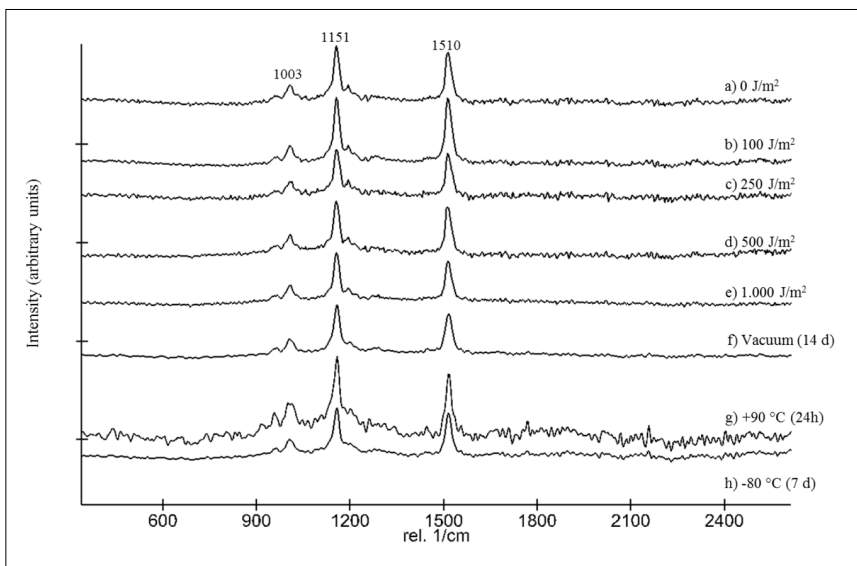

FIGURE 8 | Stacked Raman spectra showing the effect of UV-C $254 \mathrm{~nm}$ radiation up $1,000 \mathrm{~J} / \mathrm{m}^{2}(\mathrm{a}-\mathrm{e})$, vacuum $(\mathrm{f})$, as well as $+90^{\circ} \mathrm{C}(\mathrm{g})$ and $-80^{\circ} \mathrm{C}(\mathrm{h})$ to $\mathrm{MeOH} / \mathrm{BHT}$ extracted cell homogenate of $D$. radiodurans.

and singlet oxygen, performing better than other carotenes or xanthophylls (Tian et al., 2007; Dartnell et al., 2012). Furthermore, deinoxanthin is also remarkably stable when not inside the cell, compared to other possible biomarkers such as DNA, which is more vulnerable against radiation when not protected by the cell (Leuko et al., 2011). The abilities of Raman spectroscopy to detect biomarkers such as carotenoids from samples collected in remote and extreme areas such as the Atacama Desert, Death Valley, volcanic rocks, or Antarctica have been extensively tested and verified (Edwards et al., 2005; Jorge Villar et al., 2006; Vítek et al., 2010; Winters et al., 2013). It was also shown that carotenoid signatures can be recovered from cryptochasmoendoliths, preserved microbial filaments, and relict sedimentary structures (Edwards et al., 2007). However, we also know from previous research that carotenoids are vulnerable toward oxidation and photodecomposition (Vítek et al., 2014). The detrimental effect of solar radiation on pigmentation is well established and has been previously investigated for Cyanophora paradoxa (Häder and Häder, 1989) or for corals (Brown and Dunne, 2008). This photodegradation is primarily caused by the UV-A part of the solar spectrum (Kumar et al., 2015); however, a destruction of Raman biosignatures is also commissioned by high doses of ionizing radiation (Dartnell et al., 2012) and $\gamma$-irradiation (Meeßen et al., 2017). The detrimental effect of radiation has also been demonstrated by previous space missions to LEO, where Cockell et al. (2011) report the complete disappearance of previous $\beta$-carotene Raman signatures from several phototrophic organisms. Over the history of Mars, galactic cosmic radiation and solar cosmic rays played an important role in the degradation of organic molecules near the planetary surface, should they have ever been present (Vítek et al., 2014). Calculations by Pavlov et al. (2012) suggest that organic molecules with masses greater than $100 \mathrm{amu}$ (atomic mass unit) would be destroyed in less than 1 billion years in the top $5 \mathrm{~cm}$ of Martian regolith (Vítek et al., 2014). Furthermore, analysis by Raman spectroscopy of Martian meteorites, e.g., MIL03346 which belongs to the nakhlite group, failed to identify 
any biological signature (Wang et al., 2015). However, only a diminutive amount of Martian meteorites has been analyzed, so future research may reveal signs of biological life in a meteorite.

Our results presented here suggest that 1.5 years exposure to the Mars-like solar UV spectrum is already sufficient to degrade deinoxanthin beyond detectability with Raman spectroscopy, at the investigated total fluence. To search for signs of extinct life on the surface of Mars seems therefore pointless; however, below the surface the picture may be completely different. Protected from the most detrimental environmental source, radiation, signs of earlier life may still be preserved. Caves, or other subterranean cavities, can be suspected on other planets and in particular Moon or Mars show clear photographic evidence of lave tube caves (Boston et al., 2003).

In this study we showed the successful detection of the carotenoid deinoxanthin following exposure to Mars conditions for 1.5 years simulated in space when protected from solar radiation. Even though some signals were recovered from samples exposed to solar radiation, the vast majority of carotenoids were degraded beyond detectability by Raman spectroscopy. All other tested space relevant conditions, such as temperature oscillations, vacuum, or a Martian atmosphere, had

\section{REFERENCES}

Armstrong, G. A. (1997). Genetics of eubacterial carotenoid biosynthesis: a colorful tale. Annu. Rev. Microbiol. 51, 629-659. doi: 10.1146/annurev.micro.51.1.629

Baqué, M., Verseux, C., Böttger, U., Rabbow, E., De Vera, J. P., and Billi, D. (2015). Preservation of biomarkers from cyanobacteria mixed with Mars like regolith under simulated Martian atmosphere and UV flux. Orig. Life Evol. Biosph. 46, 289-310. doi: 10.1007/s11084-015-9467-9

Battista, J. R. (1997). Against all odds: the survival strategies of Deinococcus radiodurans. Annu. Rev. Microbiol. 51, 203-224. doi: 10.1146/annurev.micro. 51.1.203

Bauermeister, A., Hahn, C., Rettberg, P., Reitz, G., and Moeller, R. (2012). Roles of DNA repair and membrane integrity in heat resistance of Deinococcus radiodurans. Arch. Microbiol. 194, 959-966. doi: 10.1007/s00203-012-0834-x

Bauermeister, A., Moeller, R., Reitz, G., Sommer, S., and Rettberg, P. (2011). Effect of relative humidity on Deinococcus radiodurans 'resistance to prolonged desiccation, heat, ionizing, germicidal, and environmentally relevant UV radiation. Microb. Ecol. 61, 715-722. doi: 10.1007/s00248-010-9785-4

Boston, P. J., Frederick, R. D., Welch, S. M., Werker, J., Meyer, T. R., Sprungman, B., et al. (2003). Human utilization of subsurface extraterrestrial environments. Gravit. Space Res. Bull. 16, 121-131.

Böttger, U., de Vera, J. P., Fritz, J., Weber, I., Hübers, H. W., and SchulzeMakuch, D. (2012). Optimizing the detection of carotene in cyanobacteria in a Martian regolith analogue with a Raman spectrometer for the ExoMars mission. Planet Space Sci. 60, 356-362. doi: 10.1016/j.pss.2011.10.017

Brown, B. E., and Dunne, R. P. (2008). Solar radiation modulates bleaching and damage protection in a shallow water coral. Mar. Ecol. Prog. Ser. 362, 99-107. doi: 10.3354/meps07439

Bustin, S. A., Benes, V., Garson, J. A., Hellemans, J., Huggett, J., Kubista, M., et al. (2009). The MIQE guidelines: minimum information for publication of quantitative real-time PCR experiments. Clin. Chem. 55, 611-622. doi: 10.1373/ clinchem.2008.112797

Cockell, C. S., Rettberg, P., Rabbow, E., and Francis-Olsson, K. (2011). Exposure of phototrophs to 548 days in low Earth orbit: microbial selection pressure in outer space and on early earth. ISME J. 5, 1671-1682. doi: 10.1038/ismej.2011.46

Cox, M. M., and Battista, J. R. (2005). Deinococcus radiodurans - the consummate survivor. Nat. Rev. Microbiol. 3, 882-892. doi: 10.1038/nrmicro1264

Dartnell, L. R., Page, K., Jorge-Villar, S. E., Wright, G., Munshi, T., Scowen, I. J., et al. (2012). Destruction of Raman biosignatures by ionizing radiation and no detectable effect on the molecule. Future missions are planned to investigate caves on Mars and by extending our search for life on Mars to the subsurface, we certainly would increase our chances to find traces of extant or extinct life on our neighbor planet.

\section{AUTHOR CONTRIBUTIONS}

SL and MB performed the experimental setup and the survival assays; SL, MB, UB, FH, and J-PdV performed Raman spectroscopic analysis; ER and AP conducted the MGR experiments; AP conducted Electron microscopy. SL, MB, FH, $\mathrm{UB}, \mathrm{ER}, \mathrm{AP}, \mathrm{PR}$, and J-PdV helped with data interpretation, scientific guidance, and preparation of the manuscript.

\section{ACKNOWLEDGMENT}

The authors thank the European Space Agency for the flight opportunity and would like to acknowledge the support of ESA (special thanks to René Demets) and of the MUSC team.

the implications for life detection on Mars. Anal. Bioanal. Chem. 403, 131-144. doi: 10.1007/s00216-012-5829-6

Dartnell, L. R., and Patel, M. R. (2014). Degradation of microbial fluorescence biosignatures by solar ultraviolet radiation on Mars. Int. J. Astrobiol. 13, 112-123. doi: 10.1017/S1473550413000335

de Vera, J. P., Boettger, U., de la Torre Noetzel, R., Sánchez, F. J., Grunow, D., Schmitz, N., et al. (2012). Supporting Mars exploration: BIOMEX in low Earth orbit and further astrobiological studies on the Moon using Raman and PanCam technology. Planet. Space Sci. 74, 103-110. doi: 10.1016/j.pss.2012. 06.010

de Vera, J.-P., Schulze-Makuch, D., Khan, A., Lorek, A., Koncz, A., Möhlmann, D., et al. (2014). Adaptation of an Antarctic lichen to Martian niche conditions can occur within 34 days. Planet. Space Sci. 98, 182-190. doi: 10.1016/j.pss.2013. 07.014

Dose, K., Bieger-Dose, A., Dillmann, R., Gill, M., Kerz, O., Klein, A., et al. (1995) Era-experiment "Space Biochemistry". Adv. Space Res. 16, 119-129. doi: 10. 1016/0273-1177(95)00280-R

Edwards, H. G. M., Herschy, B., Page, K., Munshi, T., and Scowen, I. J. (2011). Raman spectra of biomarkers of relevance to analytical astrobiological exploration: hopanoids, sterols, and steranes. Spectrochim. Acta A. 78, 191-195. doi: 10.1016/j.saa.2010.09.020

Edwards, H. G. M., Hutchinson, I. B., Ingley, R., and Jehlička, J. (2014). Biomarkers and their Raman spectroscopic signatures: a spectral challenge for analytical astrobiology. Philos. Trans. R. Soc. A. 372:20140193. doi: 10.1098/rsta.2014. 0193

Edwards, H. G. M., Jorge Villar, S. E., Pullan, D., Hargreaves, M. D., Hofmann, B. A., and Westall, F. (2007). Morphological biosignatures from relict fossilized sedimentary geological specimens: a Raman spectroscopic study. J. Raman Spectrosc. 38, 1352-1361. doi: 10.1002/jrs.1775

Edwards, H. G. M., Moody, C. D., Jorge Villar, S. E., and Wynn-Williams, D. D. (2005). Raman spectroscopic detection of key biomarkers of cyanobacteria and lichen symbiosis in extreme Antarctic habitats: evaluation for Mars lander missions. Icarus 174, 560-571. doi: 10.1016/j.icarus.2004.07.029

Fairén, A. G., Davila, A. F., Lim, D., Bramall, N., Bonaccorsi, R., Zavaleta, J., et al. (2010). Astrobiology through the ages of Mars : the study of terrestrial analogues to understand the habitability of Mars. Astrobiology 10, 821-843. doi: 10.1089/ast.2009.0440

Ghiassi-nejad, M., Mortazavi, S. M. J., Cameron, J. R., Niroomand-rad, A., and Karam, P. A. (2002). Very high background radiation areas of Ramsar, Iran: 
preliminary biological studies. Health Phys. 82, 87-93. doi: 10.1097/00004032200201000-00011

Gill, D., Kilponen, R. G., and Rimai, L. (1970). Resonance Raman scattering of laser radiation by vibrational modes of carotenoid pigment molecules in intact plant tissue. Nature 39, 371-386. doi: 10.1038/227743a0

Häder, D. P., and Häder, M. A. (1989). Effects of solar and artificial radiation on motility and pigmentation in Cyanophora paradoxa. Arch. Microbiol. 152, 453-457. doi: 10.1007/BF00446928

Hirayama, O., Nakamure, K., Hamada, S., and Kobayasi, Y. (1994). Singlet oxygen quenching ability of naturally occurring carotenoids. Lipids 29, 149-150. doi: 10.1007/BF02537155

Horneck, G., Moeller, R., Cadet, J., Douki, T., Mancinelli, R. L., Nicholson, W. L., et al. (2012). Resistance of bacterial endospores to outer space for planetary protection purposes - experiment PROTECT of the EXPOSE-E mission. Astrobiology 12, 445-456. doi: 10.1089/ast.2011. 0737

Hunter, S. E., Jung, D., Di Giulio, R. T., and Meyer, J. N. (2010). The qPCR assay for analysis of mitochondrial DNA damage, repair, and relative copy number. Methods 51, 444-451. doi: 10.1016/j.ymeth.2010.01.033

Ji, H. F. (2010). Insight into the strong antioxidant activity of Deinoxanthin, a unique carotenoid in Deinococcus radiodurans. Int. J. Mol. Sci. 11, 4506-4510. doi: 10.3390/ijms11114506

Jorge Villar, S. E., Edwards, H. G. M., and Benning, L. G. (2006). Raman spectroscopic and scanning microscopic analysis of a novel biological colonisation of volcanic rocks. Icarus 184, 158-169. doi: 10.1016/j.icarus.2006. 04.009

Kawaguchi, Y., Yang, Y., Kawashiri, N., Shiraishi, K., Takasu, M., Narumi, I., et al. (2013). The possible interplanetary transfer of microbes: assessing the viability of Deinococcus spp. under the ISS environmental conditions for performing exposure experiments of microbes in the Tanpopo mission. Orig. Life Evol. Biosph. 43, 411-428. doi: 10.1007/s11084-013-9346-1

Klein, H. P. (1999). Did Viking discover life on Mars? Orig. Life Evol. Biosph. 29, 625-631. doi: 10.1023/A:1006514327249

Kumar, B. N. V., Kampe, B., Rösch, P., and Popp, J. (2015). Characterization of carotenoids in soil bacteria and investigation of their photodegradation by UVA radiation via resonance Raman spectroscopy. Analyst 140, 4584-4593. doi: 10.1039/C5AN00438A

Lemee, L., Peuchant, E., and Clerc, M. (1997). Deinoxanthin: a new carotenoid isolated from Deinococcus radiodurans. Tetrahedron 53, 919-926. doi: 10.1016/ S0040-4020(96)01036-8

Leuko, S., Neilan, B. A., Burns, B. P., Walter, M. R., and Rothschild, L. J. (2011). Molecular assessment of UVC radiation-induced DNA damage repair in the stromatolitic halophilic archaeon, Halococcus hamelinensis. J. Photochem. Photobiol. 102, 140-145. doi: 10.1016/j.jphotobiol.2010.10.002

Marshall, C. P., Leuko, S., Coyle, C. M., Walter, M. R., Burns, B. P., and Neilan, B. A. (2007). Carotenoid analysis of halophilic archaea by resonance Raman spectroscopy. Astrobiology 7, 631-643. doi: 10.1089/ast.2006.0097

Mattimore, V., and Battista, J. R. (1996). Radioresistance of Deinococcus radiodurans: functions necessary to survive ionizing radiation are also necessary to survive prolonged desiccation. J. Bacteriol. 178, 633-637. doi: 10.1128/jb.178. 3.633-637.1996

Meeßen, J., Backhaus, T., Brandt, A., Raguse, M., Böttger, U., de Vera, J. P., et al. (2017). The effect of high-dose ionizing radiation on the isolated photobiont of the astrobiological model lichen Circinaria gyrosa. Astrobiology 17, 154-162. doi: 10.1089/ast.2015.1453

Meeßen, J., Wuthenow, P., Schille, P., Rabbow, E., de Vera, J.-P. P., and Ott, S. (2015). Resistance of the lichen Buellia frigida to simulated space conditions during the pre-flight tests for BIOMEX-viability assay and morphological stability. Astrobiology 15, 601-615. doi: 10.1089/ast.2015.1281

Pavlov, A. A., Vasilyev, G., Ostryakow, V. M., Pavlov, A. K., and Mahaffy, P. (2012). Degradation of the organic molecules in the shallow subsurface of Mars due to irradiation by cosmic rays. Geophys. Res. Lett. 39:L13202. doi: 10.1029/ 2012GL052166

Pogoda de la Vega, U., Rettberg, P., and Reitz, G. (2007). Simulation of the environmental climate conditions on martian surface and its effect on Deinococcus radiodurans. Adv. Space Res. 40, 1672-1677. doi: 10.1016/j.asr. 2007.05.022
Rabbow, E., Parpart, A., and Reitz, G. (2016). The planetary and space simulation facilities at DLR Cologne. Microgr. Sci. Technol. 28, 215-229. doi: 10.1007/ s12217-015-9448-7

Rabbow, E., Rettberg, P., Barczyk, S., Bohmeier, M., Parpart, A., Panitz, C., et al. (2012). EXPOSE-E: an ESA astrobiology mission 1.5 years in space. Astrobiology 12, 374-386. doi: 10.1089/ast.2011.0760

Rabbow, E., Rettberg, P., Parpart, A., Panitz, C., Schulte, W., Molter, F., et al. (2017). EXPOSE-R2: the astrobiological ESA mission on board of the international space station. Front. Microbiol. 8:1533. doi: 10.3389/fmicb.2017.01533

Richmond, R. C., Sridhar, R., Zhou, Y., and Daly, M. J. (1999). Physicochemical survival pattern for the radiophile $D$. radiodurans: a polyextremophile model for life on Mars. SPIE 3755, 210-222. doi: 10.1117/12. 375078

Saito, T., Ohyama, Y., Ide, H., Otha, S., and Yamamoto, O. (1998). A carotenoid pigment of the radioresistant bacterium Deinococcus radiodurans. Microbios 95 , 79-90.

Schirmack, J., Böhm, M., Brauer, C., Löhmannsröben, H.-G., de Vera, J.-P., Möhlmann, D., et al. (2014). Laser spectroscopic real time measurements of methanogenic activity under simulated Martian subsurface analogue conditions. Planet. Space Sci. 98, 198-204. doi: 10.1016/j.pss.2013. 08.019

Sghaier, H., Narumi, I., Satoh, K., Ohba, H., and Mitomo, H. (2007). Problems with the current deinococcal hypothesis: an alternative theory. Theory Biosci. 126, 43-45. doi: 10.1007/s12064-007-0004-x

Shahmohammadi, H. R., Asgarani, E., Terato, H., Saito, T., Ohyama, Y., Gekko, K., et al. (1998). Protective role of bacterioruberin and intracellular $\mathrm{KCl}$ in the resistance of Halobacterium salinarum against DNA-damaging agents. J. Radiat. Res. 39, 251-262. doi: 10.1269/jrr.39.251

Shkrob, I. A., Chemerisov, S. D., and Marin, T. W. (2010). Photocatalytic decomposition of carboxylated molecules on light exposed martian regolith and its relation to methane production on Mars. Astrobiology 10, 425-435. doi: 10.1089 /ast.2009.0433

Slade, D., and Radman, M. (2011). Oxidative stress resistance in Deinococcus radiodurans. Microbiol. Mol. Biol. Rev. 75, 133-191. doi: 10.1128/MMBR. 00015-10

Stahl, W., and Sies, H. (2003). Antioxidant activity of carotenoids. Mol. Aspects Med. 24, 345-351. doi: 10.1016/S0098-2997(03)00030-X

Sy, C., Dangles, O., Borel, P., and Caris-Veyrat, C. (2015). Interactions between carotenoids from marine bacteria and other micronutrients: impact on stability and antioxidant activity. Mar. Drugs 13, 7020-7039. doi: 10.3390/md13117020

Tian, B., and Hua, Y. (2010). Carotenoid biosynthesis in extremophilic Deinococcus-Thermus bacteria. Trends Microbiol. 18, 512-520. doi: 10.1016/j. tim.2010.07.007

Tian, B., Sun, Z., Shen, S., Wang, H., Jiao, J., Wang, L., et al. (2009). Effects of carotenoids from Deinococcus radiodurans on protein oxidation. Lett. Appl. Microbiol. 49, 689-694. doi: 10.1111/j.1472-765X.2009.02727.x

Tian, B., Xu, Z., Sun, Z., Lin, J., and Hua, Y. (2007). Evaluation of the antioxidant effects of carotenoids from Deinococcus radiodurans through targeted mutagenesis, chemiluminescence, and DNA damage analysis. Biochim. Biophys. Acta 1770, 902-911. doi: 10.1016/j.bbagen.2007.01.016

Tillett, D., and Neilan, B. A. (2000). Xanthogenate nucleic acid isolation from cultured and environmental cyanobacteria. J. Phycol. 35, 1-8. doi: 10.1046/j. 1529-8817.2000.99079.x

Toporski, J., and Steele, A. (2002). "The relevance of bacterial biomarkers in astrobiological research," in Proceedings of the Second European Workshop on Exo/Astrobiology, Vol. SP-518 (Noordwijk: European Space Agency).

Vítek, P., Edwards, H. G. M., Jehlička, J., Ascaso, C., de los Ríos, A., Valea, S., et al. (2010). Microbial colonization of halite from the hyper-arid Atacama desert studied by Raman spectroscopy. Philos. Trans. R. Soc. A 368, 3205-3221. doi: $10.1098 /$ rsta.2010.0059

Vítek, P., Jehlička, J., Edwards, H. G. M., Hutchinson, I., Ascaso, C., and Wierzchos, J. (2014). Miniaturized Raman instrumentation detects carotenoids in Mars-analogue rocks from the Mojave and Atacama deserts. Philos. Trans. R. Soc. A. 372:20140196. doi: 10.1098/rsta.2014.0196

Vítek, P., Osterrothová, K., and Jehlička, J. (2009). Beta-carotene - A possible biomarker in the Martian evaporitic environment: Raman micro-spectroscopic study. Planet. Space Sci. 57, 454-459. doi: 10.1016/j.pss.2008.06.001 
Wang, A., Korotev, R. L., Jolliff, B. L., and Ling, Z. (2015). Raman imaging of extraterrestrial materials. Planet. Space Sci. 112, 23-34. doi: 10.1177/ 0003702817721715

Wassmann, M., Moeller, R., Rabbow, E., Panitz, C., Horneck, G., Reitz, G., et al. (2012). Survival of spores of the UV-resistant Bacillus subtilis strain MW01 after exposure to Low-Earth Orbit and simulated Martian conditions: data from the space experiment ADAPT on EXPOSE-E. Astrobiology 12, 498-507. doi: 10.1089/ast.2011.0772

Winters, Y. D., Lowenstein, T. K., and Timofeeff, M. N. (2013). Identification of carotenoids in ancient salt from Death Valley, Saline Valley, and Searles Lake, California, using laser Raman spectroscopy. Astrobiology 13, 1065-1080. doi: 10.1089/ast.2012.0952

Zhang, L., Yang, Q., Luo, X., Fang, C., Zhang, Q., and Tang, Y. (2007). Knockout of crtB and crtI gene blocks the carotenoid biosynthetic pathway in Deinococcus radiodurans $\mathrm{R} 1$ and influences its resistance to oxidative DNA-damaging agents due to change of free radicals scavenging ability. Arch. Microbiol. 188, 411-419. doi: 10.1007/s00203-0070262-5

Conflict of Interest Statement: The authors declare that the research was conducted in the absence of any commercial or financial relationships that could be construed as a potential conflict of interest.

Copyright (C) 2017 Leuko, Bohmeier, Hanke, Böttger, Rabbow, Parpart, Rettberg and de Vera. This is an open-access article distributed under the terms of the Creative Commons Attribution License (CC BY). The use, distribution or reproduction in other forums is permitted, provided the original author(s) or licensor are credited and that the original publication in this journal is cited, in accordance with accepted academic practice. No use, distribution or reproduction is permitted which does not comply with these terms. 